\title{
Review of Public Administration and Management
}

\section{Four Ways Forward}

\section{Kwan Lamar Blount ${ }^{\star}$}

Department of Criminal Justice, Hill, John Jay College of Criminal Justice, New York, USA

\begin{abstract}
This is an evaluation and analysis of attrition in South Carolina police departments. The purpose of the report is to gain clarity on possible causes of attrition and offer potential approaches to mitigating and/or eliminating a current and future issue that may have adverse implications on both quantitative and qualitative services rendered by departments across South Carolina. It then proposes four ways in which departments might be capable of increasing their recruitment to restore legitimacy.

This analysis is based on data from two surveys-the Law Enforcement Management and Administration Statistics and Census of State and Local Law Enforcement Agencies surveys-collected and made available by the US Bureau of Justice Statistics between 2007 and 2013. Three measures of attrition are used: (1) retention/attrition rates, (2) replacement rates, (3) and civilian-to-officer ratios. Additionally, demographic representation is also examined (e.g. female, minority or nonwhite, educational background, pay rates, etc.). Tables containing this information can be found in the appendix.
\end{abstract}

Keywords: Policing; Reform; Public perceptions of police; Legitimacy; Alternatives to police

\section{Introduction}

Examination of attrition-related rates in the state shows some indicators below expected and/or desired averages. For instance, officerto-civilian ratios appear to be trending upward, posited as a potential warning sign. Such indicators are of concern because they have critical implications for both the quantity and quality of services rendered to communities.

For South Carolina, a multiplicity of indicators signify areas of opportunity regarding attrition and retention based on policing trends, motivations and challenges-demonstrated through human resource measures including retention rates, replacement rates, civilian-to-officer ratios, and the sum picture these rates depict. Each rate can tell an organization something about how it is faring where its human resources are concerned, as well as its areas of opportunity for improvement. In this report, the indicators are reviewed for the seven largest county and seven largest municipal policing agencies in the state.

\section{Retention Rates}

In South Carolina, retention rates were slightly higher for the sample of county agencies (avg. 88\%) than those in municipal agencies (avg. 83\%), resignations accounting for 3\% of county agencies and 6\% of municipal agencies-"other" factors taking up the remaining $9 \%$ and $11 \%$ respectively (See Appendix). When retention decreases, quantity and quality of service does likewise. This can result in costly ventures to get department back to full functionality (recruiting, training, and loss of qualified, seasoned officers, for example). The further from $100 \%$ retention an organization experiences, the costlier, more burdensome and likely are adverse operational impedance.

\section{Replacement Rates}

Aside from the Richland County Sheriff's Department, which reported zero hires or separations in 2013, five of the largest county departments reported replacement rates at or above $100 \%$, save onethe Horry County Police Department. Horry County registered a replacement rate of $56 \%$, meaning that nearly two officers ended employment there for every one that was hired in 2012. As for six of the largest city agencies (Columbia Police Department failed to report new hires), not one reached a replacement rate of $100 \%$. This indicates that all of their manpower pools shrunk in 2012. However, some caution should be noted here as, from 2007 to 2013, each of these agencies increased their number of sworn personnel, save the Mount Pleasant Police Department which saw a net reduction of force of just one officer. Either some inconsistency in reporting occurred or it may be possible that poorer replacement rates are a recent phenomenon.

\section{Civilian-to-Officer Rates}

One thing that should be accounted for is that South Carolina is a relatively small state, whose municipalities are typically smaller than that found in larger, more populous states. However, CTO rates are proportionate and allow for comparison between localities of vastly different sizes. In 2012, New York City had a population of $8,336,697$, nearly double the estimated population of the entire state of South Carolina in that same year. Its police department employs 34,454 full-time sworn officers. Still, New York City's CTO ratio, as of January 1, 2013, would have been 242 citizens per officer. If it serves as a model for urban environment CTOs, South Carolina's average large municipal jurisdiction CTO rate indicates a manpower problem. Meanwhile, the Los Angeles has a very large municipal policing agency as well as an active Sheriff's department with jurisdiction over all of Los Angeles County. The Los Angeles Police Department (LAPD) has 9,920 full-time sworn officers for a population of 3,857,799; the Los Angeles County Sheriff's Department employs 9,266 for a population of 9,962,789 people. These agencies have an approximate 389/1 and $1,075 / 1$ civilian/officer ratio, respectively. If these are more typical CTO benchmarks, than both South Carolina's cities and counties exhibit an average in keeping with other locales. However, when viewing the problem regionally as opposed to statewide, the Low country exhibits increasing CTO ratios relative to other regions in the state. This may be a cause for concern.

*Corresponding author: Kwan-Lamar Blount-Hill, Department of Criminal Justice, Hill, John Jay College of Criminal Justice, New York, USA, Tel: +18433431156; E-mail: kblount-hill@jjay.cuny.edu

Received April 25, 2017; Accepted May 09, 2017; Published May 11, 2017

Citation: Blount KL (2017) Four Ways Forward. Review Pub Administration Manag 5: 212. doi:10.4172/2315-7844.1000212

Copyright: $\odot 2017$ Blount KL. This is an open-access article distributed under the terms of the Creative Commons Attribution License, which permits unrestricted use, distribution, and reproduction in any medium, provided the original author and source are credited. 


\section{Sum of the Measures: Retention, Replacement and CTO Rates}

Retention, replacement and CTO rates all point to potential problems in retention, though the story is mixed across departments, agency-types and regions. Furthermore, none of these indicators are a universally-accepted measure for when attrition becomes a problem. Moreover, the number of authorized versus currently employed officers is a common measure used to determine a problem in maintaining manpower, and this measure was unavailable to assess given the data provided. Thus, while some indicators may point to the fact that South Carolina needs render due diligence in creating a more loyal and willing workforce, the picture is far from clear. At base, this indicates a need to invest in more precise data collection and measurement of law enforcement employment trends.

\section{Conclusion}

Continuing and sustaining an effective and qualified police workforce is an ongoing challenge for South Carolina's police departments at large. In the long run, the demand for qualified officers, and the inability to supply such officers, may place a greater strain on departments and communities that can least afford compromised policing. Further, at a time of expanded policing responsibilities and greater scrutiny of law-enforcement policies, procedures and behaviors in the spotlight, workforce deficits only serve to additionally compromise the legitimacy of those serving on the front line. These concerns are real and substantial. The current state of attrition in law enforcement cry for greater due diligence in developing tools for assessing current methods of recruitment and vetting, training and community input/evaluation vehicles (e.g. surveys, public forums, social media, etc.), as well as efforts toward providing South Carolina police officers an environment conducive to long-lasting and fruitful policing careers.

This is a broad analysis of policing issues faced by South Carolina agencies. Each region and community are challenged by its own unique set of circumstances. Therefore, while there is some standardization that must take place in managing attrition and retention, each department will need to take a look at its individual community to ensure that those unique nuances are addressed throughout its workforce planning. It is also necessary that administrators keep in mind that attrition may not always be considered a bad thing if it gets rid of unwanted and or unneeded officers and opens up opportunities to those more suited for the department. Annual evaluation should continue to be used to ensure that planning efforts are relevant to the changing needs of the times.

\section{Limitations of Report}

This report offers only a very broad view of attrition in South Carolina. This report does not offer any new data and all analysis is done based upon pre-existing data, the most recent of which is from 2013. Secondary data analyses have their own disadvantages and are subject always to primary data biases. Where departments fail to participate in data collection efforts or to collect and analyze data on their own, and where information provided is erroneous, incomplete, or inconsistent across time, substantive and meaningful analysis is always limited and the conclusions drawn from it always tentative. More research will be necessary to provide a more comprehensive inquiry into police employment, both trends and the impacts of various policies and practices influencing those trends.

Moreover, some standard information-gathering process will need to be agreed upon by law enforcement agencies and other professional bodies that work to ensure police effectiveness so that researchers have the tools necessary to give useful and useable advice to enforcement practitioners.

\section{Attrition and Retention across South Carolina Police Departments}

It is axiomatic that, in recent years, law enforcement agencies across the country have had difficulty in retaining officers, experiencing levels of unsustainable attrition in their officer ranks. This can be caused by a number of factors, including officer retirement, transition from one agency to another or from policing to some other career, and, of course, an employee's termination by his or her employing agency. The resultant cycles of attrition and replenishment through recruitment comprise the process called "turnover" [1].

While turnover/attrition has been a topic of concern for police administrators at least since the early [2], policing researchers have failed to produce a robust body of literature directing practitioners as to how to control it or even to determine whether it is a problem or not [3]. In fact, between 1974 and 1997, only thirty-four (34) such studies were reported [4].

In South Carolina, the Criminal Justice Academy (SCCJA) is particularly concerned with the loss of officers within the states law enforcement ranks. While individual departments are responsible for the hiring and firing of officers, the duty to train and certify replacements becomes the shared responsibility of the department and the SCCJA. Thus, the cost associated with such events is borne, in part, by the SCCJA. Increases in attrition rates experienced by departments across the state of South Carolina may create a strain for the SCCJA and the individual departments in terms of increased training costs, loss of job-acquired skill and expertise, the financial burdens of recruitment and vetting, strain on shrinking populations of remaining officers, and a reduction in public esteem, leading to a decrease in the quality of police service rendered, a decline in officer morale, and a threat to public safety. Therefore, it becomes important to determine when unsustainable attrition is occurring and how to mitigate it to increase rates of retention to necessary levels.

\section{Attrition vs. Retention: What's the Difference?}

Is there an understood and accepted relationship between attrition and retention? Yes. By definition they are opposites of the same human capital coin. While attrition is the measure of organizationemployee separation during a given period, retention is the measure of organization-employee tenure during a given period. Both of these measures have played critical roles in the overall effectiveness of South Carolina's policing efforts-attrition impacting the organizations' capacity to fulfill their duties in optimal time and manner within their communities and retention speaking to the KSAOs (knowledge, skill, attitudes and other characteristics) necessary to ensure qualified officers are in appropriate positions and succession plans are afforded an adequate pool of qualified candidates from which to draw. Though these two events may not necessarily correlate with one another, it may be said that one may very well indicate how an organization is faring in light of the other-whether there is cause for concern is being determined in this report by examining both events across South Carolina Police departments and comparing the results to national averages.

\section{Attrition}

Attrition is the ending of an employment relationship between the employee and employer [3]. This usually happens because of the employee's retirement, his or her voluntary resignation, or his or her termination by the employer. Attrition becomes problematic 
for policing agencies and their supporting systems when it begins to occur at unsustainable rates. Voluntary resignation may be especially disruptive and costly for a police agency when it occurs expectedly [1]. Nevertheless, even predictable instances of attrition, such as retirement, or controllable instances, such as termination, can be burdensome when not adequately planned for or coupled with sufficient replacement through recruitment [5].

Unplanned attrition causes a number of costs and disruptions, not the least of which is financial in nature. It has been estimated that the loss of an employee can cost from ninety-three to two hundred percent ( $93 \%$ to $200 \%$ ) of the departing officer's annual salary [6]. These expenses are incurred predominantly through the hiring process, particularly selection and subsequent training. If [6] 's estimation is correct, the premature loss of just one officer in each of South Carolina's seven largest counties and municipal agencies alone (just fourteen officers total) may account for nearly $\$ 1$ million in replacement costs across the state (see Appendix, Table 1).

Other costs include the drain of built up expertise and the overburdening of the remaining officers who have to pick up any slack left over. Reduced average officer experience may lead to increases in mistakes of judgment and inefficiencies in service provision as younger, more inexperienced officers come to dominant agency profiles $[3,5]$. Carefully nurtured relationships between specific officers and community residents are lost [3]. Rampant turnover also likely diminishes the agency's reputation in the overall view of the public [6]. Loss of competent officers necessitates reaching into the applicant pool to replace him or her, a pool where quality candidates are becoming increasingly difficult to find [3]. Finally, turnover begets turnover, attrition leads to loss of morale among remaining officers which leads to more attrition $[3,6]$.

\section{What does South Carolina's data reveal about its attrition rates?}

As previously mentioned, the current state of analytical study in attrition rates is sparse [3]. This is unfortunate, as there is little guidance as to how to measure attrition effectively, what rates of attrition are to be expected and what rates undesirable, what is par for the course and what should be troubling. For example, if there is, in fact, no "attrition problem" in South Carolina, any efforts to reverse normal trends in attrition and retention could prove ineffective and unnecessary. To date, the assessment of South Carolina's police employment landscape has been largely anecdotal and speculative. One aim of this report is to provide some evidence-based context to this picture. Using the 2007 and 2013 LEMAS and 2008 CSLLEA surveys, this report explores attrition in South Carolina.

The law enforcement management and administrative statistics (LEMAS) dataset is a survey of state, county and local law enforcement agencies collected by the bureau of justice statistics (BJS) from a nationally representative sample, containing all departments with greater than 100 sworn officers and a sample of smaller agencies. The LEMAS survey is cross-sectional, representing information from a snapshot in time on January 1 of a given year. The census of state and local law enforcement agencies (CSLLEA) survey uses a nationally representative sample of state and local law enforcement agencies based on the sample used for the 2007 LEMAS survey [3].

To examine South Carolina, only data from South Carolina agencies are examined in this report. Furthermore, of the fifty-five law enforcement agencies participating in the LEMAS survey from
South Carolina as of January 1, 2013, a portrait is developed using only the largest fourteen agencies in the state-the largest seven county enforcement agencies as well as the largest city agencies. Together these agencies reported employing more than half of the sworn officers accounted for in the 2013 LEMAS survey (exactly 3,863 of 6,506 ). The average number of officers in these largest agencies was 276; that is, 302 deputies, on average, for the largest sheriffs' departments and 250 officers, on average, for the largest city police departments. Table 2 (see Appendix) provides the total numbers of full-time sworn personnel for these agencies.

Because of the limited amount of study that has been done in the area of police attrition, a universal and standard way of determining whether a location is experiencing a problem with attrition has not been settled upon. Thus, one should consider several indicators when inquiring about problematic attrition.

\section{Retention}

If someone were to ask about an organization's retention rate, a common response would be to compare it to the organization's "turnover rate." Still, someone else might say it was the inverse of the turnover rate. Retention is actually the measure of certain employees over a specified period of time. According to the Society for Human Resource Management (SHRM, 2015), retention complements the turnover rate to give a clearer view of employee movement than looking at one rate or the other. The retention rate formula is:

(\# of employees who remained employed for a specified period of time / \# of employees at the start of that specified period of time) ${ }^{\star} 100$

It is imperative that the correct data is evaluated to accurately determine if departments are on a successful course to satisfying its human resource needs. Evaluating retention periodically (typically an annual event) may also help in establishing best practices for retaining the most qualified officers. If a department has a significantly high retention rate it could be said that the officers in that department are satisfied with their jobs and can feel the value that the organization places on their work.

\section{What South Carolina's data suggests about retention}

Reviewing retention rates in the largest agencies in South Carolina, they averaged slightly higher for county agencies (88\%) than for in municipal agencies (83\%). Resignations accounted for 3\% of the losses in county officers and $6 \%$ of those in municipal agencies. Other factors accounted for the remaining $9 \%$ and $11 \%$, respectively (see Appendix, Table 3).

\section{South Carolina's retention/attrition rates compared to the rest of the nation}

According to data obtained for 2008, the national rate of attrition from state and local law enforcement agencies was approximately $7.4 \%$ [3]. One measure that has been used is to obtain the number of individual agencies attrite and to divide that number by the number of current full-time sworn officers, to produce a percentage decimal [3]. Using this measure, three of South Carolina's largest county agencies, and five of the state's largest city departments have attrition rates exceeding the national average according to the 2008 BJS report (see Appendix, Table 3 ). To the extent that this paints a picture of comparatively high rates of attrition in South Carolina, [3] report confirms this as a general trend across the Southern USA.

In his study using the 2003 and 2008 LEMAS and CSLLEA surveys, 
Wareham et al. found a national attrition rate of approximately $10.8 \%$. In the current South Carolina sample, only one of the large county agencies-but still five of the municipal agencies-registered attrition rates above this level. Wareham et al. reports that voluntary resignation was, by far, responsible for the largest proportion of attrition. Nationally, the rate they found was $7.5 \%$ in 2003 and 2008. It is, of course, unclear if these voluntary resignations were really forced resignations-instances where employees are given an opportunity to resign before involuntary termination-or unexpected instances of an employee quitting. Either way, such resignations usually offer only short periods for an organization to prepare for the loss before it takes effect. Voluntary resignations, therefore, represent the most troublesome of attrition occurrences. Fortunately, if Wareham et al.s $7.5 \%$ represents a national benchmark that has carried over into 2013 and beyond, none of the county agencies in the 2013 South Carolina sample exceeded that rate of voluntary resignations, though three of the municipal agencies did, with Mount Pleasant Police Department nearly doubling it.

Comparing South Carolina's agencies to national benchmarks helps to determine abnormal attrition vis-à-vis other states. Comparing those agencies to each other allows a determination of within-state abnormalities (see Appendix, Table 3). It is important to note that Richland County Sheriff's Department reported a $100 \%$ retention rate. This may unfairly skew the average of the seven largest sheriffs' departments upward; it seems questionable that, the entire year prior to January 2013, the Richland County had absolutely no retirements, resignations or terminations of any kind among its deputies. Taking these numbers at face value, however, four county agencies have failed to keep up with their counterparts. At the city-level, three agencies fail to meet the average municipal rate of officer retention. It should be noted that using an within-state average necessarily means that approximately half of South Carolina agencies would likely to fall below it; it is, however, instructive for agencies to compare themselves to similarly situated agencies in order to assess their relative circumstances [3].

To that point, Wareham et al. found that law enforcement agencies in Southern states averaged a total attrition rate of $13.73 \%$ in 2003 and $13.90 \%$ in 2008. Only the Columbia and Mount Pleasant Police Departments exceeded this rate in 2013. Moreover, the average rate of attrition by voluntary resignation was $10.43 \%$ and $10.61 \%$ in 2003 and 2008, respectively. Only Mount Pleasant Police Department exceeded this rate in 2013. Finally, in 2003, the North Carolina Department of Criminal Justice reported that states' municipal police departments had a total attrition rate of $14.2 \%$ [5], which, again, only Columbia and Mount Pleasant Police Departments exceeded in South Carolina in 2013. No county agency exceeded that attrition rate of $12.7 \%$ reported by North Carolina in 2003.

So, compared to other Southern states, South Carolina is comparable in rates of attrition. Still, in a nationally competitive market for officers, the state is below average in its ability to retain its police officers [3] points to the possibility that the economic recession disproportionately hit Southern states, and this may explain differentials in retention and turnover between this and other regions.

\section{Understand the Moving Parts of Attrition and Retention}

For South Carolina, attrition and retention have a multiplicity of indicators that signify areas of opportunity based on policing trends, motivations and challenges-demonstrated through human resource measures including retention rates, replacement rates, civilian-toofficer ratios, and the sum picture provided by these measures. Each rate can tell an organization something about how it is faring where human resources are concerned, as well as its areas of opportunity for improvement.

\section{Replacement Rates}

One way to measure whether an agency is having challenges with attrition is to measure its ability to replace individuals whose employment is terminated or who have moved to other positions within the department. This is a measure not commonly seen in the literature, but it gives an indication as to whether the agency is able to sustain itself. If a replacement rate equals or exceeds $100 \%$, an agency has demonstrated its capacity to replace every individual that leaves and perhaps to grow beyond that point. Where replacement rates are below $100 \%$, this signifies that the agency is shrinking; more individuals have ended employment than were hired, an absolute diminishment of force size.

Table 4 (see Appendix) shows the replacement rates for the seven largest county agencies and seven largest municipal police agencies in South Carolina. Richland County Sheriff's Department reported neither separations nor new hires during 2012. Aside from this anomaly, five of the other county departments reported replacement rates at or above $100 \%$, save one-the Horry County Police Department. Horry County registered a replacement rate of $56 \%$, meaning that nearly two officers ended employment there for every one that was hired in 2012.

The city agencies tell a different story. Not one reached a replacement rate of $100 \%$, meaning that all of their manpower pools shrunk in 2012. This is a curious finding because the LEMAS was also conducted in 2007 (see Appendix). From 2007 to 2013, each of these agencies grew in terms of the number of sworn personnel, save the Mount Pleasant Police Department which saw a net reduction of force of just one officer. Thus, it may be possible that these lackluster replacement rates are a fairly recent phenomenon.

Still, viewing sustainability as a function of 2013 replacement rates, the data portend that South Carolina's city agencies have an attrition problem going forward.

\section{Civilian-to-Officer (CTO) Ratios Indicate South Carolina's Low-Country Has Attrition Problems}

Retention rates show the ability or inability of an agency to retain hired employees. Depending on the circumstances of the attrition, losing a current employee, even with its short-term costs, may be a long-term gain (Wareham et al. 2015). For example, the attrition of older, intransigent officers in favor of hiring new, more cooperative ones is cycles oft seen in cases where new administrative leaders take over an agency. Still more, retention rates say nothing about whether recruitment rates have compensated for them. On the other hand, replacement rates can present a picture of a decline in sworn force size. A decline in the size of the force is not necessarily a good or bad one. It is generally presumed that agencies should seek to grow in size and avoid shrinking, but it is likely that this presumption is incorrect under a number of circumstances. For example, a city with a decreasing population may have no need to grow its police department and may, in fact, legitimately seek to shrink it.

Thus, this report also presents an additional measure of attrition not otherwise seen in the literature reviewed. By comparing ratios of citizens to officers, one may hope to produce a measure of police capacity that accounts for changes in population as well as absolute force levels. As the number of citizens per officer increases, it may be presumed that this increase represents a stretching of police resources 
and an attendant decline in the quantity of service that may be provided per citizen, if not the quality of that service.

Table 2 (see Appendix) shows the CTO ratios of South Carolina's largest county and city agencies. In South Carolina, the average civilianto-officer ratio is 694 civilians per officer. However, that presents a skewed picture. County (rural/suburban) policing is different than city (urban/suburban) policing, and thus tends to have different police staffing patterns. When one disaggregates the county agencies from the city agencies, what one finds is that county departments have an average CTO rate of 1030, while city departments have, on average, only 358 civilians per officer living within their jurisdictions.

One thing that should be accounted for is that South Carolina is a relatively small state, whose municipalities are typically smaller than that found in larger, more populous states. However, CTO ratios are proportionate and allow for comparison between localities of vastly different sizes. For example, in 2012, the Census Bureau projected that New York City, New York had a population of 8,336,697, nearly double the estimated population of the entire state of South Carolina in that same year. Its police department is the largest local law enforcement agency in the United States, employing 34,454 full-time sworn officers according to the 2013 LEMAS, a group larger than the entire population of the City of Myrtle Beach as projected in 2012. Still, New York City's CTO ratio, as of January 1, 2013, would have been 242 citizens per officer. If it serves as a model for urban environment CTOs, South Carolina's average large municipal jurisdiction CTO rate indicates a manpower problem.

In California, the City of Los Angeles has a very large municipal policing agency as well as an active Sheriff's department with jurisdiction over it and all of Los Angeles County. The Los Angeles Police Department (LAPD) has 9,920 full-time sworn officers for a population of 3,857,799; the Los Angeles County Sheriff's Department employs 9,266 for a population of $9,962,789$ people. Thus, these agencies have an approximate $389 / 1$ and 1,075/1 civilian/officer ratio, respectively. If these are more typical CTO benchmarks, than both South Carolina's cities and counties exhibit an average in keeping with other locales.

Another way to determine adequate CTO ratios would be to compare South Carolina CTO ratios in one jurisdiction to another of like kind within the state. Table 5 presents the percent by which the largest county and city agencies deviate in their CTO ratios from their group average. As with within-state retention averages, in-state CTO averages necessarily relegate approximately half of the agencies below the fifty percentile. Still, comparison between similarly situated agencies on this point can help an administration assess its agency's circumstances relative to those most like it [3].

One final use of CTO ratios is to compare trends over time. Unfortunately, the sample of agencies included in LEMAS changes from one administration to the next, in accordance with differences in eligibility criterion and changes in agency circumstances. Prior to 2013, the most recent LEMAS survey conducted was as of January 1, 2007. In this administration, only twenty-six agencies from South Carolina were represented, and these did not include the sheriff's departments in South Carolina that were included in the 2013 LEMAS. This means that temporal analysis could only be conducted using municipal agencies. What is beneficial, however, is that not only can the 2007 LEMAS be compared to the 2013 administration of the LEMAS survey, but one may also use the 2008 CSLLEA to establish a fuller picture of the trend line.

Reviewing the trends in CTO ratios from 2007 to 2008 to 2013, one observes that only the Rock Hill and Mount Pleasant Police
Departments had increases in CTO ratios, and then only modestly so (5\% and 2\% respectively; see Appendix, Table 6). By 2013, Rock Hill's police department had reversed this trend but three agenciesCharleston, North Charleston, and Mount Pleasant-registered increases in CTO ratios, the latter two dramatically so. If higher civilian-toofficer ratios are indeed indicative of lower qualities and quantities of service provision, it is noteworthy that the three municipal agencies whose CTO rates increased are located in the region traditionally known as the Low-Country; the others represent the Midlands, Pee Dee and Upstate regions. Interestingly, what one sees is an increase in the civilian/officer ratios in the Low-Country agencies (hypothesized to be bad) and a simultaneous decrease in these ratios in all other areas. There could be several explanations for this, but if one looks only to rapid population growth as a causative factor, population estimates from 2007 to 2012 show unpatterned growth throughout the state, in contrast to the concentrated increases in civilians per officers in the Low country (see Appendix, Table 7).

\section{Filled versus unfilled positions}

The available data does not allow for an analysis of how many authorized positions went unfilled in 2013 or beyond. However, prior administrations of the LEMAS survey collected information regarding how many positions an agency was authorized to fill. Unfortunately, the 2013 LEMAS does not collect this information and, as the other datasets are more than seven years old at this point (e.g., 2008 CSLLEA), it would not be very instructive to conduct an analysis of proportion of authorized positions unfilled. This is, however, yet another measure of whether an agency has an attrition problem identified in the current literature.

\section{Sum of the measures}

Retention rates, replacement rates and CTO ratios all point to an attrition problem. Taking all of the measures examined, it appears that South Carolina has an attrition problem, whether statewide, isolated to its cities, or the Low country region. The question then becomes, "Why?"

\section{Attrition as an area of opportunity}

In turning to the question of why a location is experiencing issues in retaining its police officers, the literature points to several potential explanations. First, current literature provides some indication as to agency characteristics that appear correlated with retention troubles. For instance, rural agencies-of which South Carolina has many-typically have greater trouble retaining officers than urban or suburban agencies [3]. Municipal agencies have higher attrition through voluntary resignations than county agencies, which have higher resignations than state agencies. The reverse is true with regard to attrition through more controlled routes such as retirement. Larger agencies tend to have an easier time retaining officers than smaller ones.

Still, the question remains: Why? What circumstances prompt individual officers to decide to leave their jobs for employment elsewhere? This question is of paramount importance. However, to answer it completely and specifically with regard to South Carolina, much more detailed data would need to be available and much more complex analysis carried out (with its attendant costs in time, effort and resources). In lieu of that, what can be done is a review of what current literature suggests the causes of attrition are and speculation as to whether these causes are at work in the state.

\section{Compensation: Low pay}

Low pay may increase the likelihood of attrition, but is not 
determinative. When police chiefs are asked what is the top reason for agency departures, opportunities for better salaries is often listed as the top cause for employee attrition in their agencies [5]. In their analysis of motivations to apply among minority and female candidates. In their study, [7] demonstrated that salary actually increases in importance to officers as time goes by [8] found that a $\$ 7,300$ increase in starting pay contributed to an increase of $89 \%$ in female applications for police officer positions, and a $145 \%$ increase in minority applicants. Many smaller agencies (presumably offering lower salaries and lesser benefits) lose their officers not to other professions but rather to larger, moreresourced agencies $[6,8]$. This, in turn, has been said to offer evidence that compensation can be determinative in officer retention [4].

Compensation includes more than take home pay in dollars and cents. Employees not only consider direct pay, but also the robustness of benefits packages and the flexibility of their working conditions. Where an employee discerns that his or her current employer compensates them fairly through pay and fringe benefits, the level of increased pay needed for an employee to leave increases; Financially strapped or unhappy employees will transfer jobs for a mere five percent increase in pay, satisfied employees do not make the leap until closer to twenty percent increases are offered [5].

This alludes to a finding that is common throughout the studies of retention or recruitment: Direct compensation is not the end-all, be-all factor in determining whether an individual will attempt to enter into the field of law enforcement or whether an officer will stay. In fact, salary itself has often been ranked as one of the least important determinants of an individual's decision to leave or stay with a policing agency [7].

Examination of the salary information obtained from the 2013 LEMAS seems to bear this latter point out. Taking each of the aforementioned measures of attrition, one discovers that the relationship between compensation and retention is not so clear. For instance, of the seven largest county agencies in the state, Horry County Police Department has the lowest replacement rate; yet it ranks in the middle of the group in terms of minimum entry-level salary and guarantees the highest minimum pay for its sergeants (see Appendix, Table 8). In contrast to the county agencies, no city reaches a $100 \%$ replacement rate, despite the fact that the municipal agencies, on average, offer higher salaries than the counties. Greenville, Charleston, and Dorchester Sheriffs' Departments, along with Horry County's Police Department, do not differ widely from the other three counties in salaries offered as a group, though this group comprises those county agencies with poorer retention rates. While the lowest paying municipal agency-Greenville Police Department-is one of the cities with a lower retention rate, so are Columbia and Mount Pleasant, which offer relatively high salaries for the state. Of course, in terms of CTO trends, the Lowcountry cities ranked least favorably while comprising the highest paying block of agencies in South Carolina.

Considering the hypothesis that officer transfers to other law enforcement agencies (a "lateral hire") is motivated largely by salary increases, one need only look at the dubious evidence in Table 9 (see Appendix). Mount Pleasant Police Department pays a slightly higher minimum entry-level salary than North Charleston Police Department, but NCPD hires laterally at a rate nine times that of MPD. Charleston County pays better than Dorchester County, yet Dorchester hires 59\% of its new hires laterally, while Charleston only hires $29 \%$ of its new hires from other agencies.

Of course, these are not definitive analyses. For instance, differences in the percentage of new hires that are brought on laterally may be a function of both outside officer interest in an agency and the organization's desire for prior experienced officers. Moreover, agencies with larger numbers of new hires can have smaller proportions of lateral hires, even if their absolute numbers are higher. Lateral hiring may be influenced by an agencies proximity to other competitive agencies; those agencies that stick out from among their geographic competitors may be more likely to serve as concentrations of lateral interest. As for the influence of salary, it may be that comparing salaries dollar for dollar between South Carolina agencies does not account properly for differences in the cost-of-living across the state. Furthermore, South Carolina agencies do not compete solely with themselves. It may be that the pull of higher salaries more often draws officers out of the state than to other agencies within South Carolina. What is curious when considering these factors, however, is that entry-level compensation has increased for nearly every municipal agency from 2007 to 2013, in several instances beyond the rate of inflation, and yet these data present no discernable pattern in determining which will have higher or lower rates of attrition by one or another of the measures proposed (see Appendix, Table 10; Bureau of Labor Statistics Inflation Calculator).

\section{Competition from other professions}

Job demands and agency rigidity can contribute to attrition. Individuals working in policing may be lured away by offers of better employment opportunities in other agencies or other careers. [5] notes, the economy is the "greatest external factor influencing employee attrition." Based upon a theory of motivation where incentives are prime, it is argued that employees are always assessing the relative benefits of competing employers and that employers looking to retain a competitive advantage must remain ever vigilant in attending to worker attitudes and desires.

Other job opportunities may be alluring for a number of reasons. Perhaps individuals seek less demanding jobs; less distressing occupations; more flexible hours; work overload; and conflicting or grueling work demands, among others, contribute to officers decision to resign [9]. As such, attrition should decrease in times when employment is scarce and increase when employment opportunities abound elsewhere. [9] found that minority applications for hire increased as a direct result of rises in the unemployment rate.

Indeed, the unemployment rate in South Carolina has fallen in recent years, reaching to 8.6 in the final months of 2012 and attrition, as previously indicated, seemingly increased in that timeframe. However, more complex analysis would have to be done in order to assert evidence of a link between outside employment opportunities and attrition in law enforcement. And it is less than clear why one would forsake a prior choice to enter law enforcement for some other career path.

One potential culprit is the stress of the job. Law enforcement is undoubtedly one of the most stressful jobs available [9]. However, other jobs-such as air traffic controllers, journalists, and building constructors-have been shown to be equally stressful, if not more so, to those doing them, than policing, though these professions have not demonstrated similar struggles with attrition [10].

One other factor that many point to is time. Police officers are often called to work irregular hours in long shift blocks of 8,10 , or 12 hours at a time. In fact, 12-hour shifts are becoming the more popular choice [4]. This is not necessarily a bad trend, however, as 12-hour shifts have been shown to be more beneficial than 8-hour ones, for instance [4]. Whatever the shift length, frequent rotations in shift times have also been shown to decrease satisfaction in one's job. It may be, then, that current practices in policing combine with an already stressful job to make the work exhaustive. 


\section{Lack of promotional or developmental opportunities}

Limited opportunities for development and promotions may increase the likelihood of attrition.

The lack of opportunities to advance has oft been cited as a motivation for officers to leave an agency [4,5]. In fact, possession of greater opportunities for promotional advancement is a common selling point for larger agencies where supervisory and specialized positions are greater. Similar to limitations in promotional opportunities, agencies where there are few opportunities for advancement (e.g. specialization and special assignments, advanced training, etc.) also face obstacles to holding officers for the long-term [5]. Training opportunities are seen as critical chances for officers to improve their skillsets and hone their professional craft.

Fortunately, in the largest county and municipal agencies in South Carolina, Table 11 compares the proportion of agency positions that are supervisory. Again, it should be states that within-state comparative averages produce a metric by which necessarily about half the agencies will not meet. Reviewing the Table, agencies deviate from the average only marginally in most cases. In fact, while the county agencies with relatively fewer supervisory positions are generally those evincing indicators of attrition issues, each of the city agencies showing similarly smaller proportions of supervisor positions include only two of the three with lower retention rates, do not differ in having less than stellar replacement rates, and show increasing trends in CTO ratios. Therefore, simple analysis does not reveal a lack of promotional opportunities as the cause for declines in retention when comparing agencies in South Carolina. It is, however, uncertain if promotional opportunities out of state may be contributing to attrition in these agencies.

\section{Devaluation}

The sense that one is not valued in the workplace is a strong precursor to voluntary resignation, low performance leading to termination, and increases in overall agency attrition. Study after study has shown that among the best predictors in whether an employee will leave a police agency (or any workplace, for that matter) is his or her sense of being undervalued by his or her employer. There are several ways that this message may be communicated, not the least of which is the employee's relationship with his or her direct supervisor. In fact, of all the predictors association with job dissatisfaction, poor employeesupervisor relations is the "number one" with regard to its strong influence on the occurrence of attrition $[1,4,5,10]$. [1] found, in their study, that one's relationship with her supervisor is an even better direct predictor of job satisfaction than whether they had experienced sexual harassment. A big part of the employee-supervisor relationship is the employee's receiving timely feedback on their job performance [5]. [1] found that job satisfaction was actually composed of both intrinsic and extrinsic satisfaction, where the former concerned the person's perception of their own performance and the latter perceptions of the agency's management. Intrinsic satisfaction was the more important of the two, and was directly influenced by whether an employee received positive feedback regarding their work. Positive reinforcement has a direct impact on employee satisfaction and performance.

After direct supervisor relationships, agency leaders show their value to their officers by engaging them in charting the course for the organization and putting effort toward securing "buy-in" from their employees into the agency's overall mission and direction [5]. Frequent administrative changes made without officer input are a significant predictor of work-related stress among officers [4]. Stress is, itself, a contributor to attrition rates. Moreover, the cultivation of a generally welcoming agency environment is a major contributor to retention; for example, one study found that poor work conditions and bad management were stronger influencing factors for work-related stress than police officers' exposure to violence or human misery $[9,10]$, among others, Storch and Panzarella, Newman and Rucker-Reed). The support one gets from his or her colleagues-while certainly not as critical as that from his or her supervisor-is associated with job satisfaction and the intent to voluntarily resign $[1,10]$. Thus, the notion of espirit de corps still serves a function in reducing attrition. Even the equipment and material resources that an agency invests in for its officers can send a signal as to how much these workers are truly valued $[5,10]$.

\section{Poor job-person fit}

Where employees are ill-suited for the job or begin to feel unfulfilled in performing it, attrition rises. Research indicates that up to a quarter (25\%) of newly-hired officers should be expected to leave their agencies within three years [5]. Several factors contribute to this, but poor fit between the employee and the employing agency appear to be perhaps the strongest in the early period of an officer's career [5]. Beyond the basic match between minimum skills required and the individual's attributes, job satisfaction-defined as a positive appraisal of one's job or experiences-has been shown to be a critical dimension of the decision to remain on the job $[1,9]$. Some findings have found only moderate relationships between the two, but others have demonstrated a much stronger correlation. Either way, job satisfaction appears to be an important factor in promoting retention over attrition, as well as work quality and productivity $[4,9,10]$.

Employee engagement is therefore more than just a function of involving officers in helping to chart an agency's course; it requires an effort to create opportunities for officers to engage in their daily work and find interest and challenge in it [5]. This is especially true in the modern law enforcement context, where increasing numbers of officers bring baccalaureate and advanced levels of education and training. Attending to the desires of these officers requires an agency to be sensitive to offering opportunities for the offices to address their "higher-ordered" needs (see Appendix, Table 12).

It should be heartening that among these higher-ordered needs is the need to feel as if one is contributing positively to society, a core value in policing [11]. In fact, this desire remains high even after several years on the job, when more practical considerations have already come to fore. Thus, police administrators should be concerned with providing a work environment where individuals can focus on the altruistic and motivating aspects of police work.

Job satisfaction appears to be infectious; as one perceives the overall levels of morale declining, the individual's job satisfaction appears to subsequently decline [4]. Moreover, for some reason, job satisfaction appears to decline among police officers over time in some cases $[4,9,10]$. In fact [9] found a very specific pattern: High satisfaction for officers at the beginning of their career, followed by decreased satisfaction among those with ten to fifteen years of service, and then an increase in satisfaction for officers serving beyond fifteen years. While this finding appears hopeful in that satisfaction seems to return after fifteen years of service, what may actually be happening is substantial loss of officers during the less satisfied period, resulting in only the happiest of officers remaining. This is concerning on multiple levels: (1) Younger officers often look to more experienced ones for guidance, and a decreased level of satisfaction may influence the satisfaction of younger employees; (2) Decreased satisfaction increases the likelihood of voluntary resignation, leading to the drain in experience that 
comes from older officers leaving the force; (3) Lower proportions of experienced officers germinates all of the problems with attrition that have been elucidated above, including declining quality of service to the public, less informed decision-making, and the reduction in deep community ties and relationships.

\section{Mitigation, limitation or elimination through the use of SMART processes}

Having shown that South Carolina is in need of a plan to confront attrition in its police rank, and having identified five areas most likely to influence rates of attrition, the question then becomes, "What are the options facing departments with attrition and retention challenges in South Carolina? This report puts forward six proposals designed to allow agencies to address this issue.

1. Improve officer recruitment, selection and onboarding methods/ processes

2. Make sure to develop an effective, comprehensive succession plan that embraces and supports professional and personal development to grow and maintain a qualified human resource pool

3. Train supervisors to monitor and combat turnover intentions

4. Institute a morale management program

5. Increase opportunities for specialization

6. Raise salaries and improve current benefits packages.

\section{Improve officer recruitment, selection and onboarding methods}

Recruitment is arguably the first step to mitigating attrition, while suring up retention. Improvements in recruitment and selection of quality officer candidates are imperative. In the long-term, one of the best strategies for increasing retention is to do the hard work of making excellent hiring decisions on the front end. Three factors stand out as instructive on this accord. First, seek candidates that show evidence of having desired a career in policing in the past. The best way to do this is to determine where your candidates are and how they can be reached most effectively and timely. For example, if studies/surveys show that most policing candidates can be found on college campuses then connecting with college campuses to set up recruiting booths or sending a representative to speak to classes may be a strong option. On the other hand, of Career Builder or Indeed.com show a large number of hits for individuals looking to become police, then one might suggest opening an account with these sites to get viewings from around the world, not merely the local venues. Still, local platforms should not be negated as participation in police-related youth clubs, studying criminal justice in college, or volunteering at the local department show that an individual has not simply "drifted" into policing and could conceivably both interested and qualified.

Second, during the vetting stage, ensure that interviews and discussions about the nature of policing and organizational expectations are succinct, specific realistic and comprehensive-this might include a panel interview comprised of varying ranks within the department, as well as department psychologist. Vaunting the job and inflating expectations of recruits only sets the officer up for job-expectation mismatch later on, increasing the likelihood of their voluntary resignation or poor performance. Be authentic in describing what will be expected and what the experience will likely be, and this will weed out uninterested recruits before they don the uniform. Finally, conduct behaviorally-based interviews. In this format, you can create real-life scenarios, present realistic fact patterns and expose the candidate to the realities of policing. Afterwards, give them an opportunity to thoroughly consider the nature of the job (pros and cons), responsibilities, expectations, growth opportunities and compensation and benefits. The clarity and understanding of what's ahead will give those ill-suited to policing the chance to discover the misfit before hiring the more expensive parts of the hiring process is completed.

After the recruiting is done and selections have been made, a well-organized onboarding process may solidify a healthy and fruitful employment relationship. Onboarding is the process by which a department successfully acclimates its new-hires to their new and challenging work environment, which includes its culture (both social and performance aspects) and a mentor to guide new-hires and offer them a positive point of entrance.

\section{An effective, comprehensive succession plan}

The importance of an effective, comprehensive succession plan cannot be iterated enough. A comprehensive succession plan will ensure that top qualified personnel are groomed and ready to assume key roles within the department as needed-right people, right position, right time, little dispute. The depth and viability of a department's resource pipeline may be the difference between a fully-functioning team at all times and a flailing team that continuously fights its way through existence. This plan will include those officers who have potential and the right KSAOs (knowledge, skill, attitude and other characteristics) to step into positions in the event of expected or sudden departures.

There are few instances that bare the marks of unpreparedness as separation and vacancy within an organization. These are often some of the most critical, conspicuous and stressful times. And, with the changing compositions of and demands placed on many workforces (mainly dealing with the consequences of lean times), these organizations can ill-afford strains or gaps. For police departments, "all hands on deck" is crucial, sometimes a real matter of life and death, trust and legitimacy or peace and anarchy.

A few steps should be used in developing a succession plan:

1. Create a talent/skill audit for ranks/positions within the department

2. Share the audit results with everyone or area(s) that will have an impact on the growth and development of those entering and remaining with the department (be sure to include the police academy) to ensure comprehensiveness

3. Evaluate how these requirements are obtained and or developed within the department

4. Stakeholder collaboration should be used to develop the plan (this may consist of internal and external groups), remember the community has a vested interest in this plan

5. Create a personnel list that shows organizational structure and requirement necessary for moving into various positions

6. Make sure your professional and personal development plans support the department's needs, but is flexible enough to consider future organizational structuring

\section{Supervisors}

Train supervisors to recognize, monitor and combat attrition sore spots. It was noted earlier that most important agency-associated reason for an officer's departure is a poor relationship with his or her supervisor. Officers in today's police departments require both positive 
and critical feedback, in real time and frequently. These skills can be taught during supervisory training and courses, reinforced during infield supervisory training, and constantly re-emphasized in leadership meetings and supervisory staff gatherings.

[1] note that diagnosing "turnover intentions" through tracking "turnover behavior" is a convincingly effective way at reducing actual turnover rates. Departments must develop systematic ways to counteract officer inclinations to leave, and this requires having individuals skilled at detecting and addressing officers who indicate, through their behavior, that they are unhappy or withdrawing from the organization. These encounters should be amiable, low-pressure and private, and yet should seek to glean information about what caused the intention to leave to arise as much as what it might take to have the employee recommit to the agency.

Policing is traditionally a paramilitary culture, which espouses toughness and sanction as the primary sources of motivation from supervisors. Thus, a program emphasizing positive reinforcement from supervisory staff is likely to challenge the inclinations of the current supervisors in place.

\section{Morale management program}

Institute an agency-wide morale management program. Providing such chances allow for individual officer investment in the agency, leading to greater commitment, as well as communicating a message of respect for officer opinions and intellectual abilities. This can be done through creating agency task forces, committees, and advisory councils. Officers who demonstrate great competence and expertise in an area of importance should be utilized to provide training and courses to their fellow officers, giving them yet another platform to establish themselves as valuable professionals. Moreover, line officers should be consulted before embarking on major administrative innovations. Eliciting opinions regarding things like the best shift arrangements or the institution of a new community policing strategy will convey the message that the agency's employees are valued.

Officers cannot merely be given opportunities to involve themselves in advisory bodies; these bodies must be seen as actually having an impact on agency activities. This means a necessary ceding of some decision-making by the Chief and his or her immediate subordinates. Moreover, in day-to-day patrol activities, officers should be trusted with a great degree of autonomy. If time and care are taken in the hiring and training stages of the officer's career, he or she should have the professional skills to determine the best ways to handle calls for service, patrolling assigned beats, and maintaining order. A sense of autonomy has been correlated with greater job satisfaction and increased productivity.

Additionally, [5] advises employers to seek to retain a positive "employer brand." Departments that are known for treating their employees well, offering high compensation, providing good equipment and opportunities for training, promising varied and interesting experiences and maintaining high morale are the types of agencies that officers tend to pursue employment with and refrain from leaving. Administrators should not neglect to highlight the service opportunities that policing offers. Remember, across gender, racial, and age differences, officers consistently rank the opportunity to assist others as a primary reason for their desire to become officers and their satisfaction with the job.

In recent work, Blount-Hill (in preparation) has posited that an important consideration for police agencies and their employer brand is their organizational legitimacy. Legitimacy is defined as that quality which inspires deference and obedience in a person to an authority. Recent scholarship has suggested that individuals may view an agency's identity in several ways: For instance, through its professional identity as representative of the policing profession, or through its societal identity, as an enforcer of conventional social norms. Blount-Hill suggests that individual officers tend to identified as autonomous beings, agents of the department, representatives of police everywhere, employees of the government, cogs in the criminal justice system, enforcers of the law, and symbols of societal values. Blount-Hill further suggests that individuals explicitly or explicitly conflate these identities or distinguish them, depending upon which role seems to be eclipsing the others in a given situation.

This is important in the case of employed officers as it is with the public in general. [12] suggests that police officers themselves have a view of their own legitimacy tied to their overall perception of their role value. This, in turn, may be tied to overall job satisfaction, especially in policing which has, as its draw, the provision of an opportunity to fulfill a call "higher than oneself" and to attain honor and prestige as a result. Thus, agencies will want to ensure they protect their employee brand and associated legitimacy by encouraging conflation of their brand with that of respected employees and other institutions, distinction between themselves and less respected bodies. Moreover, agencies will do well to diligently guard the reputation of their agency as a single entity, and to make its character clear and distinctive.

\section{Specialization}

Increase opportunities for specialization. Officers who are provided opportunities for more training, for example, are more likely to remain satisfied with the job. The composition of individual development plans can assist in giving officers direction in how to move their careers in desired directions within the agency and communicate the agency's desire to place the officer in his or her aspired roles. Assignments to specialty units or special duties provide opportunities to increase the officer's stature in the agency even when formal promotions are limited. This is especially important for officers in the middle of their career, when research says officers begin to lose interest and satisfaction in their jobs.

Increased training opportunities will necessarily mean organizing work shifts and staffing patterns so that officers away for training will be covered by their colleagues during their absence. Therefore, this need to fill in where officers are being trained will necessarily require some small increase in budget to pay for it.

\section{Compensation}

Raise salaries and benefits packages to outmatch other agencies, especially out-of-state, taking into account cost-of-living. If prior literature on the utilitarian calculus of employees is accurate, one of the foremost ways of showing that a department values its employees is to compensate them at or greater than competing markets. Departments must strive to maintain competitive compensation packages, which may include several combinations of economic advantages outside of straight pay.

\section{Deciding where to start}

For agencies which see multiple opportunities for improvement in their current efforts to address potential problems in their retention of officers, a quick five-factor assessment matrix can assist in determining where one might start. The matrix provided is a generalized one, so caution is advised in relying upon it without taking care to consider 
the peculiarities of the specific agency involved. For example, in some cases, these recommendations are already in place and thus not in need of replication. In others, the framework for one or more of the recommendations is already in place or being put into place, making its ease of implementation greater or cost lesser. In other cases, the need for organizational infrastructure is prohibitive, while in others abundant resources exists to implement new programs now that administrators have some means for direction. Of course, an overarching concern is always feasibility. Fortunately, inner-departmental attrition-reduction policies are hardly a public political matter. And, for the purpose of this report, unworkable policy alternatives have been avoided. Therefore, the five-factor matrix takes into account the following concerns:

\section{- Factor 1: Minimizing attrition}

- Factor 2: Maximizing officer satisfaction

- Factor 3: Maximizing ease of implementation

\section{- Factor 4: Minimizing cost}

\section{- Factor 5: Minimizing time to implementation}

In this matrix, each factor is assigned equal importance, though, again, specific agency conditions dictate whether some should be given greater credence than others. The matrix works by assigning a relative ranking to each alternative, from one (1) to six (6), with 1 representing the highest (best) rank in that category of concern. At the end, the sum of these rankings is totaled to give agencies with absolutely no way of determining a starting point a place to start (Table 1).

Table 1: The concerned five-factor matrix.

\begin{tabular}{|c|c|c|c|c|c|c|}
\hline & Factor 1 & Factor 2 & Factor 3 & Factor 4 & Factor 5 & Total \\
\hline $\begin{array}{c}\text { Improved } \\
\text { Recruitment }\end{array}$ & 1 & 2 & 5 & 5 & 5 & 18 \\
\hline Succession Plan & 2 & 3 & 6 & 2 & 4 & 17 \\
\hline $\begin{array}{c}\text { Supervisor } \\
\text { Training }\end{array}$ & 5 & 6 & 1 & 1 & 1 & 14 \\
\hline $\begin{array}{c}\text { Morale } \\
\text { Management }\end{array}$ & 3 & 1 & 3 & 3 & 6 & 16 \\
\hline $\begin{array}{c}\text { Specialization } \\
\text { Compensation/ } \\
\text { Benefits }\end{array}$ & 6 & 5 & 4 & 4 & 3 & 22 \\
\hline
\end{tabular}

Considering these, the end goal of each recommendation is to minimize attrition. Making more careful and circumspect hiring decisions in the first place will be the single most important step in ensuring an agency's ability to retain officers once hired. Engaging those officers after hire in composing a plan to advance them toward their career goals is a critical second step. Along the way, it will be important to manage the morale of these individuals and the organization as a collective, to stop the infectious nature of bad feelings about, and low commitment to, the department. Raising compensation and the value of benefits offered will help to stave off outside competition for good, satisfied and productive officers. Providing training for supervisors will reduce not only officer attrition, but will also eliminate the need for officers to seek reassignment even within the agency. Finally, opportunities for specialization go a long way toward imbuing a sense of value to an employee and providing a sense of belonging to the enforcement community.

In making changes to reduce attrition, police administrators will most assuredly be seeking ways to simultaneously increase general job satisfaction among officer ranks. Doing so is not only a protective factor against attrition, but it also improves officer productivity and the quality of service to the public. Implementing a moral management plan and improving recruitment strategies at the outset will likely have the most dramatic impact on assuring a satisfied officer cadre, though all of these are designed to improve satisfaction to some degree. Each of these policies require some organizational effort in implementation, though supervisor training is often relatively easy to do and increases in compensation packages are harder in terms of cost, but easier in terms of the decision-making. If cost is a concern for agencies, implementing a supervisor training program that emphasizes methods of detecting and addressing turnover intentions is likely the least costly, followed by a concerted effort to develop succession plans for the department's officers. Finally, supervisor training is also relatively quick to implement; it merely takes the adoption of a number of already available management-training modules as course outlines and a short period of time to administer. Increasing compensation too can be a quick action, though often budgetary realities belie this presumption.

For agencies where there is no organized attrition-reduction plan in place, instituting a supervisor training program with particular focus on addressing turnover intentions is likely the place to start. Morale management and succession planning are more medium-range endeavors that can provide big payoffs once implemented.

\section{A word on demographics: Attrition by special charac- teristics}

Beyond a concern about overall agency attrition rates, police administrators are often dually concerned with maintaining sufficient levels of persons in various demographic categories important to $[8,13]$. Immediately, the question of racial parity comes to mind when discussion police officer demographics. Indeed, this is a concern for police resource managers, as research continuously demonstrates that public perceptions of equity in police agency ranks increases the esteem in which the department is held. Moreover, gender parity is of importance as well. Policing is a male-dominated profession, and departments have long struggled to increase their proportions of female sworn officers [6]. Additionally, cultural changes have mainstreamed groups that were once deemed socially outcast [13]. As these constituencies begin to assert greater public visibility, policing departments should seek to reflect their proportions in police ranks. Nowhere is this more evident than in the case of "sexual minorities" (e.g., gay, lesbian, bisexual, transgender, queer and androgynous populations). Beyond these more traditionally considered individual traits, employment researchers have found that agency administrators must also consider the cultural differences in age cohorts. Officers who have come of age at different times grow up with different expectations for employee-employer relationships, ultimately impacting their satisfaction with work arrangements and interactions with (usually) older supervisors and administrators. Furthermore, the character of these age cohorts, including their concerns, preoccupations, and expectations, change over time.

\section{Considering generations}

Police administrators should consider the different character traits of various generations under their command. Anthropological research is clear that different generations have different "personalities," generally shared ways of viewing the world and operating in it that permeate every aspect of their lives [5]. For instance, the paramilitary style of many police departments is at odds with the prevailing personality of "Generation X" [8]. Additionally, many in that generation have engaged in what were once disqualifying activities in their youth, including minor use of illicit drugs and the commission of criminal misdemeanors. Hiring from this pool has already caused many enforcement systems to relax their eligibility standards. Complicating the matter, these 
personalities mature as time passes, changing their outlooks and focal concerns. For example, younger officers of any generation tend to place greater emphasis on base salary, while shifting to a focus on benefits (including family packages) and retirement plans over time.

\section{Gender Representation}

In South Carolina, gender parity is generally above the national average, but declining from 2007 to 2013, and not reflected in supervisory ranks. Despite assumed differences and obvious physical differentiations, women officer have been shown to perform every bit as competently as male officers. What is more, studies have shown that female officers tend to have similar motivations in police-work as males $[7,9,11]$. Thus, it would appear that the biggest disparities in female experiences in law enforcement and those of males come from external factors (e.g., gender discrimination, sexual harassment) $[1,8]$. These external factors may be exacerbated by the lack effort on the part of managers to combat sexism, the isolation of low numbers of like individuals, and the contribution of preconceived suspicions about the unfairness with which female officers are treated $[8,10]$. Distressingly, female officers have been shown to have higher rates of turnover, attributed to these very causes $[1,4]$. However, that these do not represent gender-inherent challenge is encouraging, as it shows that administrators can focus more on eradicating discriminatory features of their agencies over constructing special or preferential conditions for women, with little concern of a diminution in the quality of police service from increasing females in the ranks.

The commission on accreditation for law enforcement (CALEA) is a nationally recognized body that certifies whether agencies meet minimum standards derived from policing best practices. CALEA recommends that police agencies seek to reflect the composition of their communities in their ranks. One way of determining gender parity in police ranks is through constructing a proportional representation index (PRI). This tool measures the proportions of a given demographic within the police force and compares it to that population's proportions in the community at large. Where there is parity, the instrument produces a score of one (1); overrepresentation produces a score of greater than one, while under-representation a score lower than one (1) $[7,8,11]$.

Using the PRI tool, none of the largest county and city agencies in South Carolina reached gender parity (see Appendix, Table 13). Their PRIs ranged from 0.15 to a high of 0.41 . Notably, only four of the fourteen agencies examined fell below the national average of approximately 0.23 gender parity. So, then, while this sample of South Carolina agencies does not have gender parity, they also do not have seem to have a problem relative to agencies elsewhere. Nevertheless, two findings arose that were not as positive. First, five of the six counties for which gender ratios were available for supervisors, and four of the seven city agencies reported having lower proportions of female supervisors than female officers, though in some cases these differences were small (see Appendix, Table 14). As for demographic trends (which could only be conducted for the city agencies), five showed declines-even if slight-in the proportion of female officers over time (see Appendix, Table 15).

\section{Minority officers}

In South Carolina, few agencies have achieved racial parity and, in fact, are regressing to less representative profiles, especially with regard to proportions of Black officers. Racial parity is seen as important for a number of important reasons, most critically to improve the perception of the police with minority groups that have traditionally seen law enforcement cynically [14], as instruments of harassment, abuse and injustice. Increased diversity in police ranks is hypothesized to improve perceptions of police legitimacy and engender goodwill and cooperation in minority neighborhoods [11]. Unfortunately, police agencies have traditionally had minorities be underrepresented in their officer ranks [8].

A persistent finding in studies on the matter has been that minority police officers and their white counterparts have very similar motivations for entering and remaining in policing. For example, while a few studies have found that Black officers actually have greater job satisfaction, most have found only non-significant (either statistical or practical) differences between racial groups $[7,9]$. To the extent that race differences have been demonstrated, these have largely been attributed to external factors-like in the case of female officers-as opposed to inherent racial differences [8]. Therefore, as with women, agencies would do better to focus on reducing the organizational pressures that insidiously disadvantage minority officers than to place attention on special or preferential strategies for minority recruitment and retention.

In South Carolina, the proportion of minority officers in the largest county and city agencies range from $5 \%$ to $33 \%$ (see Appendix, Table 16). To test whether the largest county and city police agencies in South Carolina were in keeping with CALEA's recommendation that departments reflect their communities; a PRI instrument was constructed to measure racial parity (see Appendix, Table 17). It should be noted that studies show larger agencies having an advantage in achieving racial diversity over smaller agencies [8]. While greater or lesser quantities of minorities does not equate to racial parity with the community being served, it is likely that larger agency advantages in minority recruitment make it easier for them to achieve racial parity. However, the PRIs in this South Carolina sample do not bear this pattern out. The smallest municipal police agency, Mount Pleasant Police Department, is the only agency of the fourteen to have achieved racial parity or beyond with the community it serves. Dorchester County Sheriff's Department, one of the smaller of the county agencies, was the only other agency of the fourteen that came within ten percent (10\%) of reaching parity.

For this report, PRIs were constructed for the non-White population at large, and specifically for Blacks and Hispanics separately. Examining the PRIs for these groups, only two agencies reached parity for each of them. Dorchester County Sheriff's Department and Mount Pleasant Police Department reached African American parity between their agencies and the communities they serve. Charleston Police Department and did so with regard to Hispanics.

One troublesome finding was that the proportions of minority officers in the municipal agencies, while not having achieved parity in 2013, were decreasing in many agencies from 2007 to 2013 (see Appendix, Table 18). The situation becomes even more alarming when reviewing the attrition rates broken down by racial group (see Appendix, Table 19). Three of the agencies showed declines in their proportions of Hispanic officers. The real surprise is that every-everymunicipal agency for which trends could be computed showed declines in the proportion of Black officers. Black communities have consistently ranked as among the most cynical in terms of their trust in police, and yet departments seem to be moving toward eliminate Black officers from their ranks. Moreover, where declines in Black or Hispanic officers occur, these are made up not through an influx in another minority group; almost invariably, these minority officers are replaced by white officers. In terms of racial parity, this suggests that South Carolina may have a minority attrition problem. 
While these groups are certainly distinctive, it is interesting to note that prior studies have found their motivations for entering policing to be markedly similar to one another [7]. Thus, strategies to recruit and retain Black officers may have the unintended effect of recruiting Hispanic officers as well, and vice versa. As previously mentioned then, attrition may be staved by agencies engaging in activities to further recruitment efforts of minority officer candidates and then simply buffeting them from the attriting effect of race-based discriminatory practices that can arise within closed organizations.

\section{Final remarks}

[15] argued that the current state of administrative data availability for policing agencies is, in a word, abysmal. This is of concern not only to researchers, who desire access to information as a basis for their work, but also to police administrators and city managers who rely on the evidence generated from such research to inform their policy decisionmaking. Fortunately, this state of affairs can be addressed and improved by individual departments and support and oversight bodies such as the SCCJA. A concerted effort on the part of the law enforcement community and outside governing officials, in collaboration with academic institutions and research centers, could produce a cache of policing-related data designed to produce useable and useful research attuned to the specific needs and questions articulated by practitioners in the field.

This report is a first step in contributing to this collective effort. This collaborative effort between individual researchers, the SCCJA and John Jay College's Research and Evaluation Center, has forged a starting point for police research generally, and specifically in the context of employment, retention and attrition in the field, to address the particular conditions present in South Carolina. Methods of measuring retention and attrition are explored and proposed, which should be of use to researchers and practitioners alike in determining attrition levels and benchmarks for concern. Recommendations to cope with attrition problems once detected are put forward as a framework for agencies to adapt to their specific needs and for employment analysts to build upon. What is needed is continued investigation into this subject, bolstered by better data availability and more sophisticated analysis. This will take investment in commitment, time, and resources, and the partnership of academia and administration, but the fruit of the labor should be rewarding for both.

\section{References}

1. Brough P, Frame R (2004) Predicting police job satisfaction and turnover intentions: The role of social support and police organisational variables. New Zealand J of Psychol 33: 8-16.

2. Citing Phelan (1991) Harris and Baldwin (1999) point out that even "conservative" estimates of replacement cost puts the price at around $\$ 20,700$ (calculated using the Bureau of Labor Statistics inflation calculator).

3. Wareham J, Smith BW, Lambert EG (2015) Rates and patterns of law enforcement turnover: A research note. Crim Justice Policy Rev 26: 345-370.

4. Julseth J, Ruiz J, Hummer D (2011) Municipal police officer job satisfaction in Pennsylvania: A study of organisational development in small police departments. Int J Police Sci Manag 13: 243-254.

5. Orrick D (2008) Recruitment, retention, and turnover in law enforcement. Alexandria, VA: International association of chiefs of police.

6. Drew J, Carless SA, Thompson BM (2008) Predicting turnover of police officers using the sixteen personality factor questionnaire. J Crim Justice 36: 326-331.

7. Raganella AJ, White MD (2004) Race, gender, and motivation for becoming a police officer: Implications for building a representative police department. J Crim Justice 32: 501-513.

8. Jordan WT, Fridell L, Faggiani D, Kubu B (2009) Attracting females and racial/ ethnic minorities to law enforcement. J Crim Justice 37: 333-341.

9. Miller HA, Mire S, Kim B (2009) Predictors of job satisfaction among police officers: Does personality matter? J Crim Justice 37: 419-426.

10. Martinussen M, Richardsen AM, Burke RJ (2007) Job demands, job resources and burnout among police officers. J Crim Justice 35: 239-249.

11. White MD, Cooper JA, Saunders J, Raganella AJ (2010) Motivations for becoming a police officer: Re-assessing officer attitudes and job satisfaction after six years on the street. J Crim Justice 38: 520-530.

12. Tankebe J (2013) Viewing things differently: The dimensions of public perceptions of police legitimacy. J Crim 51: 103-134.

13. Coleman E, Cheurprakobkit S (2009) Police hiring and retention of sexual minorities in georgia and texas after Lawrence v. Texas. J Crim Justice 37: 256-261.

14. Blount Hill, K, Peirce J. Curing Cynicism: Testing the impact of cure violence on legal cynicism. Manuscript in preparation.

15. Wilson JM, Heinonen JA (2011) Advancing A police science: Implications from a national survey of police staffing. Police Quarterly 14: 277-297. 